\title{
A Educação Ambiental e o Ensino de Química no Estudo da Separação de Misturas
}

\author{
La Educación Ambiental y la Enseñanza de Química en el Estudio de la \\ Separación de Mezclas
}

\section{Environmental Education and Teaching Chemistry in the Study of Mixture Separation}

\author{
Rosangela Inês Matos Uhmann ${ }^{1}$ \\ Fernanda Seidel Vorpagel ${ }^{2}$ \\ Fabiane de Andrade Leite $^{3}$
}

\begin{abstract}
Resumo
Apresentamos neste estudo as vivências que se tornaram experiências de prática docente possibilitadas pelas atividades realizadas durante o Estágio Curricular Supervisionado de Química de um Curso de Licenciatura de uma Universidade pública. Destacamos quatro momentos direcionados para o estudo contextualizado dos processos de separação de misturas em atenção à Educação Ambiental, junto a duas turmas do $1^{\circ}$ ano do Ensino Médio durante o processo de constituição docente. O olhar para o processo formativo do ser professor foi registrado por meio das escritas reflexivas realizadas em portfólio, sendo que todo o processo vivenciado permeou pelos aspectos do planejamento, análise, reconstrução e constituição. Enfim, a formação se constitui reflexiva e atenta a Educação Ambiental quando vivenciada na ação docente do professor do ensino de química.
\end{abstract}

Palavras-Chave: Educação Básica. Estágio de Docência. Socioambiental.

\section{Resumen}

En este estudio se presentan las vivencias que se han convertido en experiencias de práctica docente posibilitadas por las actividades realizadas durante el curso curricular supervisado de química de un Curso de Licenciatura de una Universidad pública. Destacamos cuatro momentos dirigidos al estudio contextualizado de los procesos de separación de mezclas en atención a la Educación Ambiental, junto a dos clases del primer año de la Enseñanza Media durante el proceso de constitución docente. La mirada hacia el proceso formativo del ser profesor fue registrada por medio de las escrituras reflexivas realizadas en cartera, siendo que todo el proceso vivido permeó por los aspectos de la planificación, análisis, reconstrucción y constitución. En fin, la formación se constituye reflexiva y atenta a la EA cuando vivida en la acción docente del profesor de enseñanza de química.

Palabras claves: Educación básica. Etapa de Docencia. Social y ambiental.

\begin{abstract}
We present in this study the experiences that became experiences of teaching practice made possible by the activities carried out during the chemistry supervised curricular internship of a Public University Degree Course. We emphasize four moments directed to the contextualized study of the processes of separation of mixtures in

\footnotetext{
${ }^{1}$ Doutora em Educação nas Ciências pela Universidade Regional do Noroeste do Estado do Rio Grande do Sul UNIJUI. IJUI/RS E- mail: rosangela.uhmann@uffs.edu.br

${ }^{2}$ Graduação em Química Licenciatura pela UFFS, Campus Cerro Largo, RS. E-mail:

vorpagelfernanda@gmail.com

${ }^{3}$ Graduação em Química Licenciatura pela UFFS, Campus Cerro Largo, RS E-mail: rafaela.gunzel@gmail.com
} 
attention to Environmental Education, next to two classes of the 1st year of High School during the process of teacher constitution. The look at the formative process of being a teacher was recorded through the reflective writings carried out in the portfolio, and the entire process was permeated by the aspects of planning, analysis, reconstruction and constitution. Finally, the training is reflexive and attentive to EE when it is experienced in the teaching activity of the professor of chemistry teaching.

Keywords: Basic education. Teaching Internship. Socio-environmental.

\section{Introdução}

A escola, espaço propulsor de conhecimentos e inerente à formação dos cidadãos que tomarão decisões futuras acerca da humanidade têm a incumbência de abordar holisticamente os aspectos que visam à constituição de indivíduos críticos e conscientes. Dessa forma, visamos a partir do estudo sobre a vivência no Estágio Curricular Supervisionado de Química, tratar do ensino de química com articulação a Educação Ambiental, no contexto da Educação Básica. A vivência de experienciar a ação docente possibilitou, a partir do estudo dos processos de separação de misturas a contextualização com a Educação Ambiental.

A vivência formativa foi desenvolvida em uma escola localizada na região das Missões, no estado do Rio Grande do Sul. Destacamos que, no processo de estágio foram dedicadas 52 horas de docência em sala de aula. O recorte desta prática pedagógica, em questão, ocorreu em duas turmas (A e B) no $1^{\circ}$ ano do Ensino Médio, contendo respectivamente, 34 e 25 alunos.

Com o propósito de investigar a prática docente, efetuamos o recorte de quatro aulas que versam sobre os processos de separação de misturas vinculados a Educação Ambiental. Esse recorte se justifica, pelo fato de entendermos que as aulas precisam contribuir para a formação de significativas experiências docentes. Partindo desse pressuposto, a Educação Ambiental é um tema transversal que perpassa todos os componentes curriculares do ensino. Além disso, é compreendida como um processo por meio da qual construímos valores sociais, conhecimentos, habilidades, atitudes e competências voltadas para a conservação do meio ambiente, que é essencial para a qualidade de vida (BRASIL, 1997).

Desta forma o ensino de Química não pode desvincular-se de questões socioambientais, até porque isso não seria possível, visto que ela integra processos que explicam inúmeros fatores, como, do tratamento de água. A intenção não é apesentar somente 
os conceitos para solucionar os problemas ambientais, a questão vai além, levando os alunos a uma reflexão sobre a origem e o desenvolvimento do problema.

Nesse sentido, a necessidade de buscar nos alunos a sensibilização quanto ao uso adequado dos recursos naturais e a preservação ambiental se originou frente a problematização da minimização dos efeitos antrópicos. Seguindo essa perspectiva, Loureiro afirma que ao "[...] desprezar a cotidianidade e o indivíduo faz com que queiramos, paradoxalmente, transformar o mundo sem mudar a nós mesmos, o que seria a suprema demonstração de vaidade ou a simplista crença de que as estruturas mudam mecanicamente os indivíduos" (2006, p. 133).

As atividades desenvolvidas em sala de aula, acerca dos aspectos de separação de misturas e sua relação com a Educação Ambiental levam em consideração o acompanhamento do pensamento global, o que faz com que não seja um processo estanque. Nessa direção, o diálogo pedagógico em sala de aula abordou aspectos coletivos, políticos, econômicos e sociais. Dessa maneira, os conceitos químicos de separação de misturas foram contextualizados com a temática ambiental, consequentemente, fortalecendo a intrínseca relação entre o ensino de Química e a Educação Ambiental. As aulas desenvolvidas no estágio foram previamente planejadas a partir de planos de aulas com fundamentação teórica. Assim, a atividade aqui relatada é um recorte da vivência docente respectivo a uma reflexão acerca das perspectivas teóricas e práticas trabalhadas nas aulas e na universidade.

Desse modo, organizamos uma prática baseada no estudo do tratamento de água, com ênfase aos métodos de separação empregados nesse processo. Assim, as atividades se voltaram para o estudo dos processos de separação de misturas, etapas necessárias para tratar a água e visita para a Estação de Tratamento de Água (ETA). O desenvolvimento da atividade sempre ocorreu de forma contextualizada. O que teve por objetivo, proporcionar aos alunos o desenvolvimento da aprendizagem dos conceitos de separação de misturas presentes no tratamento de água, significando a decantação, filtração, floculação e flotação, com vistas a articular a Educação Ambiental.

Dessa maneira, a intenção que norteia este estudo decorre do interesse de fundamentar o processo de ensino e aprendizagem dos conceitos científicos, muitas vezes não compreendidos pelos alunos, por meio da contextualização com aspectos cotidianos. Destacamos que as atividades pensadas em relação à Educação Ambiental na formação inicial e continuada de professores, possibilitam novas perspectivas de ensino. Essa prática tem contribuído no desenvolvimento de um olhar crítico sobre o papel do professor em sala de aula, a qual propõe a abordagem de desenvolvimento de procedimentos próprios ao exercício 
da docência. A vivência de experienciar a docência, convergiu como um momento diferenciado de inter-relação professor e aluno por meio das aulas desenvolvidas.

\section{Metodologia}

O desenvolvimento da atividade foi proporcionada durante o Estágio de Docência em Química, esse desenvolvido em duas turmas do $1^{\circ}$ ano do Ensino Médio de uma escola pública. Para tanto, o estudo traz um recorte de quatro (4) aulas de um total de 52 aulas (50 minutos cada) planejadas. A atividade foi pensada e orientada na Licenciatura em que priorizamos o contato dos alunos com aspectos da sua realidade.

As aulas foram organizadas em quatro momentos. No primeiro, ocorreu o estudo dos processos de separação de misturas, sendo: filtração comum, filtração a vácuo, decantação, sifonação, centrifugação, levigação, catação, peneiração, flotação, floculação, ventilação, separação magnética, extração por solventes, destilação simples e fracionada. O estudo desses conceitos, em especial da filtração comum, decantação, flotação e floculação, aconteceram por meio de uma aula expositiva, experimental e dialogada. No segundo momento, dialogamos sobre um vídeo explicativo para entender como acontece o tratamento de água em uma ETA.

No terceiro momento, visitamos a Companhia Riograndense de Saneamento (CORSAN), localizada na mesma cidade da escola onde desenvolvemos a atividade. O processo de tratamento foi explicado, no local, por um responsável da CORSAN. No quarto momento, ocorreu o debate em sala de aula sobre os aspectos estudados e vivenciados, a fim de estabelecer a intrínseca relação entre Educação Ambiental e o ensino de Química. As reflexões, acerca de todas as atividades pedagógicas desenvolvidas foram registradas em portfólio pelos alunos de forma individual.

\section{Análise das experiências vivenciadas}

A Educação Ambiental ocupa um papel estratégico para a mudança de hábitos, entendimentos e ações dos seres humanos, especialmente, no que diz respeito a questões socioambientais. Acreditamos que a educação constitui o eixo articulador para aprofundar a temática ambiental e com esse movimento conceber novas práticas de conscientização e preservação ambiental. Além disso, articula os aspectos sociais, políticos e econômicos. 
Com esse olhar, articulamos o ensino de Química, especificamente, a significação dos processos de separação de misturas com as questões socioambientais. Compreendemos que os conceitos químicos precisam ter relação com o dia a dia dos alunos, pois, a Educação Ambiental: “[...] bem ensinada e bem aprendida tem de ter relação com a vida das pessoas, o seu dia a dia, o que elas veem e sentem, o seu bairro, a sua saúde, as alternativas ecológicas" (MINC, 2005, p. 72). Assim, também de acordo com Galiazzi (2003, p. 259) é imprescindível, "[...] entender a aprendizagem como um processo sempre incompleto, inacabado, progressivo e complexo".

Nesse sentido, ao realizamos o estudo acerca dos processos de separação de misturas, desenvolvido de forma experimental e dialogado, foi possível identificar previamente quais seriam os processos para o tratamento da água, a exemplo, da filtração comum, filtração a vácuo, decantação, sifonação, centrifugação, levigação, catação, peneiração, flotação, ventilação, separação magnética, extração por solventes, destilação simples e fracionada.

Para tal discussão foram desenvolvidos cinco experimentos (primeiro momento) imbricados com questionamentos sobre o observado em sala de aula, quantos aspectos seriam uniformes (fases), quais as misturas homogêneas e heterogêneas vendo as possibilidades de separação. Assim, as cinco misturas: $1^{\circ}$, água e sal; $2^{\circ}$, água e areia; $3^{\circ}$, água e acetona; $4^{\circ}$, água e óleo e a $5^{\circ}$ limalha e areia. Para discutir os conceitos mencionados anteriormente, foram desenvolvidos experimentos, durante o primeiro momento, a partir da composição de cinco misturas, sendo: $1^{\circ}$ água e sal; $2^{\circ}$ água e areia; $3^{\circ}$ água e acetona; $4^{\circ}$ água e óleo e a $5^{\circ}$ limalha e areia. Durante o experimento, questionamos quantos aspectos seriam uniformes (fases), quais são misturas homogêneas e quais são heterogêneas e as possibilidades de separação.

Percebemos que a atividade experimental foi favorável ao processo de ensino, pois problematizamos os conceitos a partir da realidade do estudante. A abordagem foi investigativa, não tendo a pretensão de comprovar uma teoria na prática. $\mathrm{O}$ experimento não foi apenas demonstrativo, sendo que, oportunizou a manipulação de procedimentos pelos próprios estudantes, abrindo caminho para novas indagações. Sendo assim, corroboramos as ideias de Santos e Schnetzler (2014, p. 114), ao afirmarem que: “[...] a importância da experimentação em função do seu papel investigativo e pedagógico de auxiliar o aluno na compreensão dos fenômenos químicos, propósito este que não demanda condições sofisticadas na escola". 
Para auxiliar na significação conceitual também fizemos uso do Livro Didático (LD) do $1^{\circ}$ ano do Ensino Médio utilizado pelos alunos, no qual constatamos um equívoco sobre o processo de flotação. $\mathrm{O}$ que nos fez buscar em outro material didático uma explicação para o conceito que pode ser entendido como:

uma técnica de separação de misturas que consiste na introdução de bolhas de ar a uma suspensão de partículas. Com isso, verifica-se que as partículas aderem às bolhas, formando uma espuma que pode ser removida da solução e separando seus componentes de maneira efetiva. O importante nesse processo é que ele representa exatamente o inverso daquele que deveria ocorrer espontaneamente: a sedimentação das partículas (MASS et al., 2008, p. 20).

Nessa direção, o diálogo em sala de aula contemplou para desmistificar possíveis dogmas, o que nos fez aproveitar a questão para destacar que o LD não é uma ferramenta incontestável, e que é necessário pensar em como os conceitos se relacionam com nossa vida, entendendo que: "[...] dialogar sob diferentes perspectivas permite um entendimento contextualizado frente às ações desencadeadas pelos seres humanos que se estendem do contexto específico ao global” (UHMANN, VORPAGEL, GÜNZEL, 2018, p. 250).

No estudo (segundo momento) das etapas gerais desenvolvidas na ETA, ressaltamos que o processo pode ter variações relacionadas a diferentes contextos de localização, como por exemplo, dependendo do local de captação de água se fará uso de diferentes concentrações ou produtos para o tratamento. Assim, o estudo dos processos de separação auxilia na compreensão do tratamento da água. A primeira fase, chamada de clarificação, é constituída pelas etapas de floculação, decantação e filtração. Nessa fase, a água ainda não está pronta para o consumo e precisa ser submetida à desinfecção, em que microorganismos são eliminados com a adição de cloro (ANTUNES, 2013). Cabe destacar que em algumas ETAs, a água também recebe flúor para ajudar na prevenção contra cáries nos dentes, especialmente nas crianças.

Com essa prática a articulação do ensino de Química com a Educação Ambiental fica evidente, entendendo que se hoje temos água na torneira para consumo, está passou por diversas etapas de tratamento. Atentando para o fato de que para cada copo de água tratada e por vezes desperdiçado, foram necessárias várias etapas que geram custos e, por fim compromete a questão ambiental, como um ciclo. Os questionamentos em sala de aula também se voltaram à água virtual, que é aquela, por exemplo, utilizada na fabricação de nossas roupas, mas que, por vezes, não vemos e não compreendemos. A reflexão abrangeu a discussão do quanto de água é utilizado mundialmente, e o que está se fazendo para não comprometer as futuras gerações quanto a sua escassez. 
Entendemos que é necessário à sensibilização com as questões socioambientais, pensamos, a exemplo, de todo o processo de fabricação envolvido no copo descartável, que de certa forma, é descartado sem o pensamento crítico do cuidado ambiental, como apenas mais um copo. O diálogo conduzido pela professora estagiária permitiu que os alunos se colocassem como protagonistas do ambiente e não como observadores dele. Tozoni-Reis (2008, p. 70-71), afirma: “A educação ambiental tem como pressuposto pedagógico a articulação entre o conhecimento sobre os processos ambientais, a intencionalidade dos sujeitos em sua relação com a natureza e a transformação social". Urge então, a necessidade de articulação entre teoria e prática, logo, relacionar o conhecimento com a intencionalidade e transformação. Sendo imprescindível a criticidade no processo de Educação Ambiental para uma ação humana ambientalmente responsável.

Sobre a visita, que aconteceu no terceiro momento, à CORSAN (Figura 01 e 02), os alunos tiveram a possibilidade de ver de perto as etapas necessárias para tratar a água consumida. A primeira etapa, à captação da água há $6 \mathrm{~km}$ de distância da ETA, no caso da cidade onde está situada a escola. Ao chegar, recebe a adição de sulfato de alumínio, que forma os flocos (aglutinações), esses diminuem o $\mathrm{Ph}$ e o carbonato de sódio que eleva o $\mathrm{Ph}$ da água novamente. O sulfato de alumínio é adicionado em quantidades estabelecidas de acordo com a análise da qualidade de água que provém da captação, como, a turbidez. Após esses procedimentos, acontecem à floculação e decantação, posteriormente, em dois tanques se dá a filtração (Figura 01). A última etapa compreende a adição de cloro e flúor passando a água para o reservatório que a distribui para a cidade.

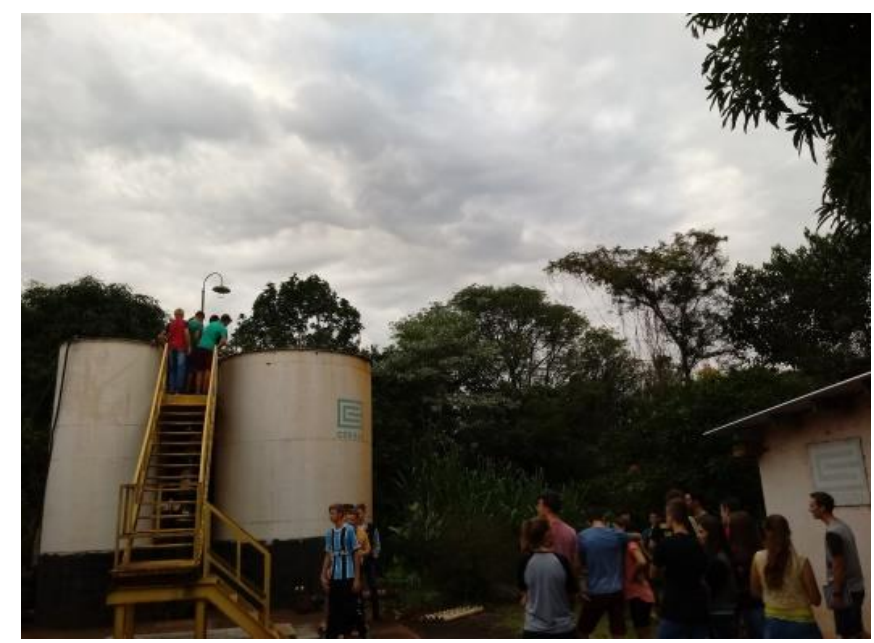

Figura 1- Tanques de filtração

Fonte: Os autores (2018).

Durante a visita percebemos que a CORSAN não tem destino correto para os resíduos gerados, sendo estes destinados para outro rio (Figura 02), o qual é fonte de captação para 
tratamento em outra cidade. Diante dessa questão, entendemos que a comunidade local precisa dialogar entre si e com os responsáveis, incluindo o poder público, para solucionar o problema.

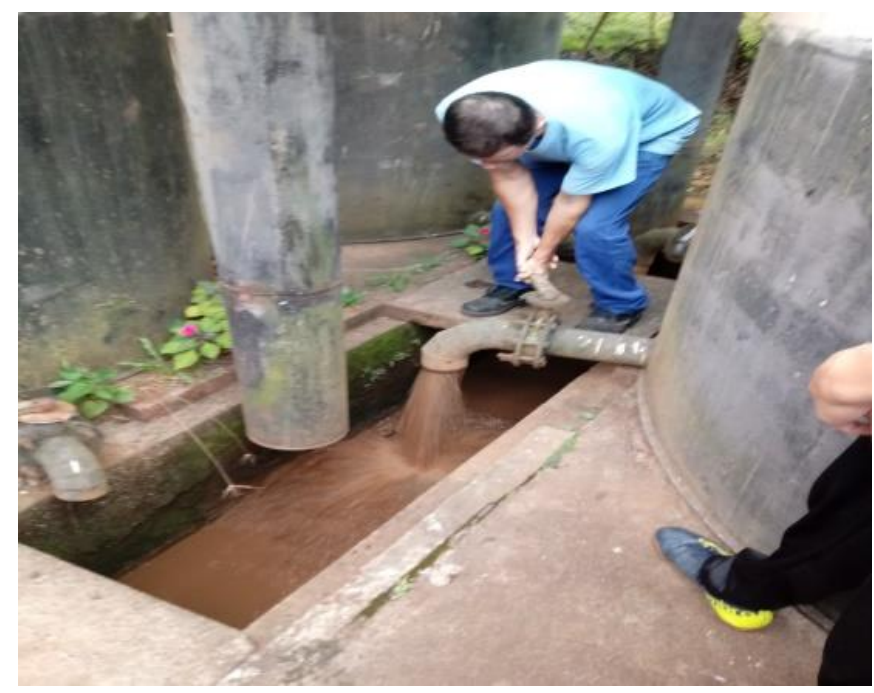

Figura 2 - Resíduos gerados

Fonte: Os autores (2018).

A intenção do diálogo em sala de aula foi exatamente para instigar os alunos na percepção de que é importante e necessário um maior envolvimento com as questões socioambientais. Ao tratarmos da temática ambiental, podemos elencar a intrínseca relação que a mesma precisa estabelecer com a política. Dias afirma que:

[...] nada se resolve sobre a temática ambiental, sem decisão política. Sabemos que, tanto no nosso país como lá fora, apesar da globalização da dimensão ambiental e da absoluta e profunda importância, já reconhecida nos foros internacionais, a classe política tem-se mostrado em relação a essa temática (e outras também) a mais despreparada de todas, a mais tacanha, obsoleta, desonesta, egoísta e desacreditada (2000, p.121).

Nessa perspectiva, o quarto momento convergiu para o debate sobre as atividades desenvolvidas com foco na Educação Ambiental e no ensino de Química. Ao tratarmos sobre a visita realizada, um dos pontos negativos destacados pelos alunos é exatamente o que retrata a Figura 02, na qual, os rejeitos do processo de tratamento da água são despejados em outro rio. A explicação por um dos responsáveis, pelo local, é de que a CORSAN já está viabilizando se adequar às normas e assim ter espaço apropriado para tratamento destes resíduos. A questão foi amplamente debatida, tendo em vista a questão socioambiental com seus aspectos econômicos e sociais. Nesse sentido, 
vislumbra-se a necessidade de explorar o contexto escolar como um todo, numa busca sem receita e sem deslumbramento, a fim de traçar um plano de ações pedagógicas que estabeleça relações de diálogo entre a prática e teoria, com a devida reflexão sobre a ação nas relações intersubjetivas, no desenvolvimento das estratégias de ensino (UHMANN, 2013, p. 46).

O processo de enfrentamento das questões socioambientais perpassa em sensibilizar a todos quanto à importância de se manter atento a temática ambiental, considerando "[...] que a realidade é múltipla e que a diversidade de métodos pode enriquecer e ampliar a compreensão do objeto de estudo" (TRISTÃO, 2004, p. 192). Cabe destacar que esse movimento de diferentes formas de pensar os aspectos da Educação Ambiental favorece a criticidade local e global.

Durante os momentos da prática pedagógica, tivemos ações recursivas para a constituição da identidade docente, visto o constante processo de formação. Precisamos estar atentos para as atividades desenvolvidas, pois entendemos que o ser professor é acarretado pela complexidade social envolvida. Quando tratamos das vivências pedagógicas que se tornam experiências é fundamental entender que nem toda vivência, seja ela de docência ou não, se torna uma experiência. Entendemos que, uma experiência é a situação que é por nós significado, o que nos toca, e não tudo o que se passa. De acordo com Larrosa: “A experiência é cada vez mais rara por excesso de trabalho. Esse ponto me parece importante porque às vezes se confunde experiência com trabalho" (2002, p. 23). O movimento de trabalho, por vezes, não significa experiência.

Desse modo, a metodologia proposta para a prática docente, visando à contextualização de conceitos químicos relacionado à Educação Ambiental é fruto de vivências formativas, essas que refletem no desenvolvimento de competências profissionais docentes. Entendemos que investigar as ações docentes seja fundamental no processo de constituição do professor comprometido com seus fazeres. Dessa forma, o portfólio foi um instrumento que permitiu a escrita de textos reflexivos acerca das atividades desenvolvidas, pois toda percepção acerca das atividades vivenciadas foram registradas pelos alunos no portfólio (Figura 03). 


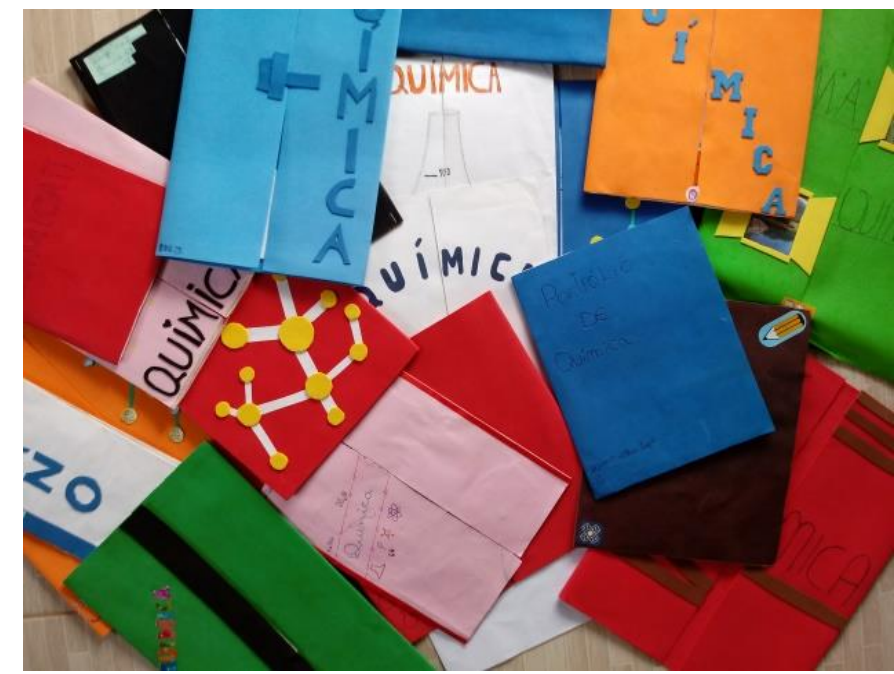

Figura 3 - Portfólios

Fonte: Os autores (2018).

O portfólio foi fundamental para a análise reflexiva, sendo que, nele constam entendimentos que podem ser usados para avaliar a didática do professor e assim reconstituir a ação docente para melhor ensinar e aprender. Não nos ateremos à organização e metodologia de desenvolvimento do portfólio, no entanto, destacamos que se constitui de escritas, desenhos e fotos sobre as práticas desenvolvidas nas aulas de química. Segundo Nunes, Sauczuk e Storer, os portfólios:

[...] são uma ótima fonte para o professor encontrar os dados mais relevantes para reflexão e análise de sua própria prática educativa e do desempenho dos alunos, pois incluem a realidade vivida em sala de aula e as práticas desenvolvidas, bem como o entendimento dos conhecimentos trabalhados (2016, p. 75).

Compreendemos que ensinar química é contextualizar os conceitos, aqui de forma especial, articulados a Educação Ambiental que necessita ser discutida em contexto escolar, visto que precisamos nos movimentar em direção da sustentabilidade ambiental. Entendemos que aproximar a química do cotidiano dos alunos, permite que eles a vejam como necessária e assim, passam a se interessar por ela.

\section{Conclusões}

Considerar as questões socioambientais no ensino dos conceitos químicos é primar pela contextualização e articulação dos mesmos, sendo necessário o debate de que a química não é algo fora de nossa realidade, como costuma ser generalizada pelos alunos na escola. A química está presente no corpo humano, vivemos devido a reações químicas que acontecem constantemente. Assim, o estudo dos processos de separação de misturas, estudados no tratamento da água e sua relação com o ambiente, possibilitou aos alunos um olhar diferente mais próximo a sua realidade. A temática em questão também precisa ser vinculada às 
temáticas que englobam questões de lixo, tratamento de resíduos, esgotos, bem como na síntese de fármacos, entre tantas outras possibilidades.

Ser professor é transformar as vivências pedagógicas em experiências, é ter momentos que nos tocam, sensibilizando a questão do ser professor. A percepção do professor diante de uma proposta didática, no que diz respeito, ao ato de ver o que o aluno internalizou sobre os aspectos tratados na atividade é gratificante. Entendemos que a Educação Ambiental articulada aos conceitos químicos, necessita desta relação entre professor e aluno com mais proximidade da realidade para avançarmos com essa questão, frente à qualidade de vida.

Nossa expectativa é de que algumas das considerações, apresentadas ao longo deste trabalho, possibilitem o desenvolvimento e a produção de novas propostas didáticas no que diz respeito à Educação Ambiental e o ensino de Química. A questão é compreender o quanto a docência pode ajudar no enfrentamento das questões ambientais, formando indivíduos críticos. O professor diante de tais desafios necessita planejar as aulas, pensar em como poderia tornar a aprendizagem significativa diante da diversidade do contexto de alunos. Ao realizar o movimento de planejamento, análise, reconstrução e constituição, acerca do desenvolvimento e olhar reflexivo sobre a prática desenvolvida, o professor se torna pesquisador de sua ação docente e com isso permite estabelecer relações de ensino e aprendizagem recíprocas.

\section{Referências}

ANTUNES, Murilo Tissoni. Ser Protagonista: química. São Paulo: Sm, 2013.

BRASIL. Ministério da Educação. Secretaria de Educação Fundamental. Parâmetros

Curriculares Nacionais. Ciências. Brasília: MEC/SEEF, 1997. Dísponivel em: <http://portal.mec.gov.br/seb/arquivos/pdf/livro01.pdf>. Acesso em: 29 mai. 2018.

DIAS, Genebaldo Freire. Educação Ambiental: Princípios e Práticas. 6. ed. São Paulo: Gaia, 2000.

GALIAZZI, Maria do Carmo. Educar Pela Pesquisa: Ambiente de Formação de Professores de Ciências. Ijuí: Unijuí, 2003.

LARROSA, JorgeBondía. Notas sobre a experiência e o saber de experiência. Revista Brasileira de Educação, São Paulo, n. 19, jan/fev/mar/abr. 2002. Disponível em: <http://www.scielo.br/pdf/rbedu/n19/n19a02.pdf>. Acesso em: 17 jul. 2018.

LOUREIRO, Carlos Frederico Bernardo. Trajetória e Fundamentos da Educação Ambiental. 2. ed. São Paulo: Cortez, 2006. 
MASS, Luciana et al. Fundamentos e Aplicação da Flotação como Técnica de Separação de Misturas. Química Nova na Escola, Porto Alegre, v. 1, n. 28, p.20-23, maio 2008. Disponível em: $<$ http://webeduc.mec.gov.br/portaldoprofessor/quimica/sbq/QNEsc28/05-CCD7106.pdf $>$. Acesso em: 17 jun. 2018.

MINC, Carlos. Ecologia e Cidadania. 2. ed. São Paulo: Moderna, 2005.

NUNES, Ana Luiza Ruschel.; SAUCZUK, Eduarda.; STORER, Franciele Rodrigues. O portfólio como instrumento para a avaliação na educação infantil. In: DELLA JUSTINA, Lourdes Aparecida.; LIMA, Bárbara Grace Tobaldini de.; OLIVEIRA, Juliana Moreira Prudente de. Interfaces entre avaliação, aprendizagem e ensino. Cascavel: Edunioeste, 2016. Cap. 4. p. 65-91.

SANTOS, Wildson Luiz Pereira dos.; SCHNETZLER, Roseli Pacheco. Educação em química: compromisso com a cidadania. 4. Ed. Ijuí: Unijuí, 2014.

TOZONI-REIS, Marília Freitas de Campos. Educação Ambiental: natureza, razão e história. 2. ed. Campinas, São Paulo: Autores Associados, 2008.

TRISTÃO, Martha. A Educação Ambiental na Formação de Professores: redes de saberes. São Paulo: Annablume, 2004.

UHMANN, R. I. M.; VORPAGEL, F. S.; GÜNZEL, R. E. Livros Didáticos de Química em foco na Educação Ambiental e Alimentar. Revista Eletrônica do Mestrado em Educação Ambiental, Rio Grande, v. 35, n. 1, p.242-259, abr. 2018. Disponível em: <https://periodicos.furg.br/remea/article/view/7256/5193>. Acesso em: 28 mai. 2018.

UHMANN, Rosangela Inês Matos. Interações e Estratégias de Ensino de Ciências: com foco na Educação Ambiental. Curitiba: Appris, 2013. 